\title{
Potential value of GCM-based seasonal rainfall forecasts for maize management in semi-arid Kenya
}

\author{
James W. Hansen ${ }^{\mathrm{a}, *}$, Ashok Mishra ${ }^{\mathrm{b}}$, K.P.C. Rao ${ }^{c}$, Matayo Indeje ${ }^{\mathrm{d}}$, Robinson Kinuthia Ngugi ${ }^{\mathrm{e}}$ \\ a International Research Institute for Climate and Society, The Earth Institute, Columbia University, 61 Route 9W, Palisades, NY 10964-8000, USA \\ ${ }^{\mathrm{b}}$ Agricultural and Food Engineering Department, Indian Institute of Technology Kharagpur, Kharagpur (W.B.) 721 302, India \\ ' ICRISAT-Nairobi, P.O. Box 39063, Nairobi, Kenya \\ ${ }^{\mathrm{d}}$ The MDG Centre, East and Southern Africa, World Agroforestry Centre, P.O. Box 30677-00100 GPO, Nairobi, Kenya \\ ${ }^{\mathrm{e}}$ University of Nairobi, Department of Range Management, P.O. Box 29053, Nairobi, Kenya
}

\section{A R T I C L E I N F O}

\section{Article history:}

Received 11 September 2008

Received in revised form 16 March 2009

Accepted 31 March 2009

Available online 7 May 2009

\section{Keywords:}

General circulation model (GCM)

Seasonal climate forecast

Crop simulation models

Risk

Kenya

\begin{abstract}
A B S T R A C T
We estimate the potential value of general circulation model (GCM)-based seasonal precipitation forecasts for maize planting and fertilizer management decisions at two semi-arid locations (Katumani and Makindu) in Southern Kenya. Analyses combine downscaled rainfall forecasts, crop yield simulation, stochastic enterprise budgeting and identification of profit-maximizing fertilizer $\mathrm{N}$ rates and stand densities. October-February rainfall predictions were downscaled from a GCM, run with both observed and forecast sea surface temperature boundary conditions - representing upper and lower bounds of predictability - and stochastically disaggregated into daily crop model inputs. Simulated interactive effects of rainfall, $\mathrm{N}$ supply and stand density on yield and profit are consistent with literature. Perfect foreknowledge of daily weather for the growing season would be worth an estimated $15-30 \%$ of the average gross value of production and $24-69 \%$ of average gross margin, depending on location and on whether household labor is included in cost calculations. GCM predictions based on observed sea surface temperatures increased average gross margins $24 \%$ at Katumani and $9 \%$ at Makindu when labor cost was included. At the lead time used, forecasts using forecast sea surface temperatures are not skillful and showed nearzero value. Forecast value was much more sensitive to grain price than to input costs. Stochastic dominance analysis shows that farmers at any level of risk aversion would prefer the forecast-based management strategy over management optimized for climatology under the study's assumptions, despite high probability (25\% at Katumani, 34\% at Makindu) of lower returns in individual years. Results contribute to knowledge of seasonal forecast value in a relatively high-risk, high-predictability context; utility and value of forecasts derived from a GCM; and risk implications of smallholder farmers responding to forecasts.
\end{abstract}

(c) 2009 Elsevier Ltd. All rights reserved.

\section{Introduction}

Dependence on uncertain rainfall and exposure to unmitigated climate risk are major obstacles to efforts to sustainably intensify agricultural production and enhance rural livelihoods in the drylands of sub-Saharan Africa. Climate shocks such as drought and flooding lead not only to loss of life, but also long-term loss of livelihood through loss of productive assets, impaired health and destroyed infrastructure. The uncertainty associated with climate variability is a disincentive to investment and adoption of agricultural technologies and market opportunities, prompting the riskaverse farmer to favor precautionary strategies that buffer against climatic extremes over activities that are more profitable on average.

\footnotetext{
* Corresponding author. Tel.: +1 845680 4410; fax: +1 8456804864 .

E-mail address: jhansen@iri.columbia.edu (J.W. Hansen).
}

To the degree that climatic uncertainty adversely impacts farmer livelihoods, forecast information that reduces uncertainty has the potential to improve livelihoods, enabling farmers to intensify production, replenish soil nutrients, adopt improved technology and invest in more profitable enterprises when conditions are favorable or near average; and to more effectively protect their families and farms against the long-term consequences of adverse extremes. A number of studies based on bio-economic modeling (reviewed in Meza et al., 2008) show that advance information in the form of seasonal climate forecasts has the potential to improve management leading to at-least modest and sometimes substantial increases in expected farm profits. The same review notes a lack of quantitative studies of seasonal climate forecasts in high-risk dryland smallholder farming systems, and in regions with relatively high predictability of rainfall at a seasonal lead time. It also notes that the forecast valuation literature emphasizes categorical statistical predictors, such as those associated with the El Niño-Southern 
Oscillation (ENSO) and hypothetical probability shifts of tercile categories of the historic seasonal rainfall distribution, and provides little information on the potential value of seasonal forecasts based on dynamic general circulation models (GCMS).

Kenya's extensive arid and semi-arid lands, characterized by dependence on low ( $\leqslant 900 \mathrm{~mm} \mathrm{y}^{-1}$ ) and unreliable rainfall, are representative of the extensive dryland regions of sub-Saharan Africa. More than 70\% of Kenya's population depends on crop- and animal-based agriculture for livelihood and sustenance and, with very limited opportunity for full irrigation, will continue to do so in the foreseeable future. The October-December "short rains" season is influenced by sea surface temperatures (SSTs) in the tropical Pacific associated with ENSO (Ropelewski and Halpert, 1987; Ogallo et al., 1988; Indeje et al., 2000; Mutai et al., 1998), and by SSTs in the Indian Ocean (Goddard and Graham, 1999; Mutai and Ward, 2000). Statistical (Mutai et al., 1998; Indeje et al., 2000; Camberlin and Philippon, 2002) and dynamic (Hansen and Indeje, 2004; Friederichs and Paeth, 2006) forecast models that incorporate understanding of relationships between the atmosphere and its underlying ocean surfaces provide a moderate degree of predictability of the short rains at a seasonal lead time over much of Kenya, and credible but weaker predictability of the March-May "long rains." Research in Kenya has demonstrated that seasonal rainfall forecasts can be downscaled to the local scale relevant to farm management, and translated into forecasts of crop yields or vegetation conditions (Hansen and Indeje, 2004; Hansen and Ines, 2005; Indeje et al., 2006).

Surveys and pilot studies with farmers in semi-arid Kenya (Ngugi, 2002; Hansen et al., 2007) and similar dryland environments in sub-Saharan Africa (e.g., Phillips, 2003; Tarhule and Lamb, 2003; Ziervogel, 2004; Roncoli et al., 2009) have generally revealed a high level of awareness and interest in seasonal forecasts, and have identified a range of promising management responses. Limited access, and mismatch between farmers' needs and the scale, content, format, or accuracy of available information products and services (O'Brien et al., 2000; Ingram et al., 2002; Phillips, 2003; Archer, 2003; Ziervogel, 2004) have limited widespread use of seasonal forecasts among smallholder farmers. Smallholder farmers have reportedly adopted and benefitted from seasonal forecasts in pilot projects in semi-arid environments in Zimbabwe, Burkina Faso and southern India, where extended interaction between smallholder farmers and researchers overcame some of the communication barriers (Huda et al., 2004; Patt et al., 2005; Meinke et al., 2006; Roncoli et al., 2009).

Our objective is to contribute to understanding of: (a) the potential value of feasible seasonal forecasts in a context characterized by high-risk smallholder agriculture and relatively high predictability, (b) the potential use and value of seasonal forecasts downscaled from a GCM, and (c) the risk implications of smallholder farmers responding to forecasts. We estimate the potential value of GCM-based seasonal precipitation forecasts for maize planting and fertilizer management decisions under simplifying assumptions including expected profit maximization at two semi-arid locations in Kenya. Our results are not intended to represent the value of current operational forecasts, the potential value of forecasts for the full suite of management options available to farmers, or the value of forecasts beyond the two study locations.

\section{Methods}

\subsection{Locations}

The study considered two locations in the semi-arid Eastern Province of Kenya: the National Dryland Farming Research Centre at Katumani ( $\left.1^{\circ} 35^{\prime} \mathrm{S}, 37^{\circ} 14^{\prime} \mathrm{E}\right)$ in the Machakos District, and Mak- indu ( $\left.2^{\circ} 17^{\prime} \mathrm{S}, 37^{\circ} 50^{\prime} \mathrm{E}\right)$ in the Makuene District. Although rainfall follows a bimodal distribution, maize production in the region depends strongly on rainfall in the October-December short rains season associated with the southward propagation of the intertropical convergence zone. Maize production is risky in this semi-arid environment due in part to its sensitivity to year-to-year variability in the amount and timing of rainfall. Our study benefits from previous model-based research at the Katumani site (Probert, 1992; Keating et al., 1993; Hansen and Indeje, 2004; Hansen and Ines, 2005; Ines and Hansen, 2006). Our analyses used observed weather data from both sites, soil data only from Katumani, and prices observed in local markets at both locations.

\subsection{Value of advance information}

A standard economic definition of the value of information is the expected outcome of optimal decisions using the new information (a climate forecast in this case) minus the expected outcome of optimal decisions based on the prior information (the climatological distribution in this case). In our case, the current potential value $V_{F}$ of a seasonal rainfall forecast system $F$ for crop management is estimated from sampling historic weather realizations and forecasts:

$$
\begin{aligned}
V_{F} \cong & n^{-1} \sum_{i=1}^{n}\left(P_{T} y\left(\mathbf{x}^{*} \mid F_{i} ; \theta_{i}, \mathbf{e}_{T}\right)-C_{\mathbf{x}^{*} \mid F_{i}}\right) \\
& -n^{-1} \sum_{i=1}^{n}\left(P_{T} y\left(\mathbf{x}^{*} \mid \Theta ; \theta_{i}, \mathbf{e}_{T}\right)-C_{\mathbf{x}^{*} \mid \Theta}\right),
\end{aligned}
$$

where $P$ is crop price, $y$ is crop yield, $\mathbf{x}$ is a vector of management variables, $\mathbf{x}^{*}$ is the management strategy that maximizes expected gross margin, $C_{\mathbf{x}}$ is cost of production associated with management strategy $\mathbf{x}, F$ represents a particular hindcast or the forecast system, $\Theta$ is the climatological distribution, $\theta_{i}$ is observed weather in year $i$, $T$ is the current year, $n$ is the number of historic years sampled, and $\mathbf{e}_{T}$ represents the current value of other environmental variables limited in this case to initial soil moisture and $\mathrm{N}$ conditions. For each year of weather data, crop yield is determined as a function of observed weather and of management optimized for either the hindcast or the climatological distribution.

Skill is defined as the accuracy of a forecast system relative to a baseline that is usually taken as the historic climatological distribution. The value of a skillful forecast system results because forecasts $F_{i}$ are closer, when averaged among all years $i$, than the climatological distribution $\Theta$ to realized weather $\theta_{i}$, and hence forecast-based management strategies $\mathbf{x}^{*} \mid F_{i}$ are closer than climatology-based management $\mathbf{x}^{*} \mid \Theta$ to the management strategies $\mathbf{x}^{*} \mid \theta_{i}$ that are optimal for realized weather. The more skillful the forecast system, the closer the forecast-based management strategy is on average to management that is optimal for actual growing season weather, and the closer gross margin is to the maximum that could be achieved with perfect information. Perfect foreknowledge of daily growing season weather represents the upper limit of the value of a forecast system:

$$
\begin{aligned}
V_{F_{\text {perfect }} \cong} & n^{-1} \sum_{i=1}^{n}\left(P_{T} y\left(\mathbf{x}^{*} \mid \theta_{i} ; \theta_{i}, \mathbf{e}_{T}\right)\right. \\
& \left.-C_{\mathbf{x}^{*} \mid \theta_{i}}\right)-n^{-1} \sum_{i=1}^{n}\left(P_{T} y\left(\mathbf{x}^{*} \mid \Theta ; \theta_{i}, \mathbf{e}_{T}\right)-C_{\mathbf{x}^{*} \mid \Theta}\right),
\end{aligned}
$$

\subsection{Enterprise budget}

Gross margin was estimated with an enterprise budget. We obtained prices of production inputs from a survey of suppliers in Machakos and Makindu in 2004. At $0.32 \mathrm{~g} \mathrm{seed}^{-1}$ and two sown 
seeds per established plant (Probert et al., undated), a stand density of $1 \mathrm{~m}^{-2}$ requires $6.4 \mathrm{~kg}$ seed ha ${ }^{-1}$. Our analyses assume that farmers use calcium ammonium nitrate (CAN) at a concentration of $26 \% \mathrm{~N}$. Labor requirements are based on a 1989-1997 field experiment conducted at ICRAF's Machakos Research Station (Rao and Mathuva, 2000). We assume that labor required for sowing is proportional to stand density, and adjusted the 12 workdays per ha for departures from the $3.7 \mathrm{~m}^{-2}$ stand density reported in Rao and Mathuva (2000). In the same way, we adjusted the 46 workday ha ${ }^{-1}$ requirement for harvest and post-harvest processing and transport proportionally for departures from the reported mean $2.46 \mathrm{Mg} \mathrm{ha}^{-1}$ yield. Farmers are assumed to lack draft animals and hence hire out land preparation. Table 1 gives the prices and cost calculations used in the enterprise budget. In December 2008, 1 Kenyan shilling (KSH) was equivalent to 0.01319 US dollar and 0.00997 Euro.

\subsection{Crop simulation}

We used the APSIM v4.2 (Keating et al., 2003) model to simulate maize yield response to weather inputs. The development of APSIM was initially prompted by research in the late 1980s on soil fertility management for maize under high rainfall variability at our Katumani study location (Brian Keating, pers. commun.). Okwach and Simiyu (1999) evaluated APSIM at this location using data from a 19-season (i.e., short- and long-rains, 1990-1999) maize trial with stand density, $\mathrm{N}$ fertilizer and mulch treatments. APSIM simulated weather and management impacts on maize yield (RMSE $=0.3$ $\mathrm{Mg} \mathrm{ha}^{-1}, R^{2}=0.96$ ), soil moisture dynamics and runoff quite well. Other published validation studies in smallholder farming environments in sub-Saharan Africa emphasize response to soil fertility management, but provide some information about response to precipitation. For a 7-year experiment in semi-arid Zimbabwe, APSIM captured average yield response to $\mathrm{N}$ fertilizer well, and response to rainfall in most years (Shamudzarira and Robertson, 2002). The authors attributed discrepancies in 2 years to an unknown stress in the experimental plot in the second year, and resulting overestimation of soil water and $\mathrm{N}$ depletion contributing to overestimation of yields in the following year. APSIM captured much of the observed differences in maize yields in the longand short-rains seasons, response to fertilizer applications, and carry-over effects of $\mathrm{N}$ applied in the long rains at a humid site in Western Kenya (Kinyangi et al., 2004). High average annual rainfall contributed to low year-to-year variability of both observed and simulated yields, and apparent weak correlation between them. In a 14-year (27-season) experiment at semi-arid Machang'a, Kenya (Micheni et al., 2004), APSIM simulations followed observed above-ground biomass yields only weakly, and showed less year-to-year variability than observed. Such inconsistencies in model response to rainfall may be due to undocumented differences in how completely stresses such as pests and diseases were managed, whether soil properties were measured at the experiment sites, or how soil hydrological properties were determined. APSIM captured most of the observed response to organic and inorganic $\mathrm{N}$ applications in all of these published studies. Keating et al. (2003) summarize evaluations and applications of APSIM and its components in other contexts, published through 2001.

Required model inputs include daily weather data (minimum and maximum temperature, precipitation and solar irradiance), soil properties, initial soil water content, cultivar characteristics, planting density, and dates of planting and $\mathrm{N}$ fertilizer inputs. This study used observed daily weather data (minimum and maximum temperature, precipitation and solar irradiance) for 34 years (1968-2002) from the Katumani and Makindu stations. Rainfall records were complete at both sites. Measured temperatures and solar irradiance were available from Makindu for the entire period. At Katumani, measured temperatures were available only since 1986, and solar irradiance only for January 1986 to September 1988. Missing observations were estimated using a stochastic weather generator conditioned on rainfall occurrence (Pickering et al., 1994).

The sandy clay loam soil (Chromic Luvisols by the FAO/UNSCO classification) has plant-extractable water-holding capacity of $163.5 \mathrm{~mm}$ over its $150 \mathrm{~cm}$ depth. For each simulation year, the water balance was initialized on 1 August with soil water at $20 \%$ of capacity. Based on Keating et al. (1992), sowing was simulated the first time at least $25 \mathrm{~mm}$ of rain fell in two consecutive days within a 15 October-15 November planting window, or forced on 15 November if sowing rains did not occur. To identify optimal management, we considered four stand densities (2.2, 3.5, 4.5 and $5.5 \mathrm{~m}^{-2}$ ) at a $50-\mathrm{cm}$ inter-row spacing, and 11 calcium ammonium nitrate fertilizer application rates $(0,5,10,20,30,40,50,60$, 80,100 and $120 \mathrm{~kg} \mathrm{~N}^{-1}$ ); and selected the combination of stand density and fertilizer rate that resulted in the highest average gross margin. The range of stand densities capture the range from typical farmers' practices in the absence of fertilizer, to intensive commercial production practices, based on the experience of one of the authors (Rao) with farming in the region.

\subsection{Rainfall and yield prediction}

The ability to predict rainfall at a seasonal lead time results from the interaction between the atmosphere and the more slowly-varying ocean and land surfaces. One method for producing operational seasonal climate forecasts involves running a GCM with global sea surface temperature (SST) boundary conditions that are predicted for the same period. Our study used seasonal rainfall hindcasts derived from the GCM, ECHAM v.4.5 (Roeckner et al., 1996), developed at the Max-Plank Institute in Germany, run at a T42 (approximately $2.8^{\circ}$ ) horizontal resolution, with 18 vertical levels. The ECHAM data were from an ensemble of GCM simulations. To capture uncertainty due to initial conditions, each

Table 1

Unit prices and production costs used to calculate gross margins.

\begin{tabular}{|c|c|c|c|c|c|}
\hline \multirow[t]{2}{*}{ Resource } & \multirow[t]{2}{*}{ Unit } & \multicolumn{2}{|c|}{ Price (KSH unit ${ }^{-1}$ ) } & \multicolumn{2}{|l|}{ Total cost $\left(\mathrm{KSH} \mathrm{ha}^{-1}\right)$} \\
\hline & & Machakos & Makindu & Machakos & Makindu \\
\hline Hired labor & Day & 150 & 150 & $150(30+3.24 \mathrm{PD}+18.7 Y)^{\mathrm{a}}$ & \\
\hline Tillage (animal) & ha & 4000 & 4000 & 4000 & 4000 \\
\hline Seed ('Katumani composite B’) & $\mathrm{kg}$ & 130 & 140 & $832 * \mathrm{PD}^{\mathrm{b}}$ & $896 * \mathrm{PD}^{\mathrm{b}}$ \\
\hline Fertilizer (calcium ammonium nitrate) & $\mathrm{kg}$ & 30 & 35 & $115.4 * \mathrm{~N}^{\mathrm{c}}$ & $115.4 * \mathrm{~N}^{\mathrm{c}}$ \\
\hline Maize grain & $\mathrm{kg}$ & 16.67 & 16.67 & & \\
\hline
\end{tabular}

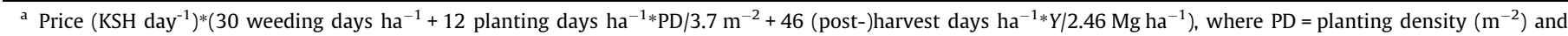
$Y=$ grain yield $\left(\mathrm{Mg} \mathrm{ha}^{-1}\right)$.

b PD (plants $\left.\mathrm{m}^{-2}\right)^{*}$ price (KSH $\left.(\mathrm{kg} \text { seed })^{-1}\right) * 10,000\left(\mathrm{~m}^{2} \mathrm{ha}^{-1}\right) / 2500$ (plants (kg seed $\left.)^{-1}\right)$.

c $\mathrm{N}\left(\mathrm{kg} \mathrm{N}\right.$ ha-1)*price $\left(\mathrm{KSH}(\mathrm{kg} \text { fertilizer })^{-1}\right) / 0.26\left(\mathrm{~kg} \mathrm{~N}(\mathrm{~kg} \text { fertilizer })^{-1}\right)$, where $\mathrm{N}=\mathrm{N}$ fertilizer application rate. 
GCM simulation run used a common set of SST boundary conditions, but different initial atmospheric conditions sampled each year from global observations on different, sequential days of the forecast month. At the time of the analyses, the combined statistical-dynamic SST forecasts that are the basis for the International Research Institute for Climate and Society's operational seasonal forecasts were not available prior to late 1997 . We therefore used both a 24-member ensemble of GCM simulations driven with observed monthly global SSTs (1968-1981 from ERSSTv1 extended reconstruction (Smith and Reynolds, 2003); and 1981-2002 from OIv1 optimal interpolation (Reynolds and Smith, 1994)), and a 12-member ensemble of GCM predictions driven with SSTs (denoted "persisted SSTs") derived by adding SST anomalies observed in August to long-term average global SSTs through the OctoberFebruary forecast period (Goddard and Mason, 2002). The resulting forecasts can be routinely available early September, which provides sufficient lead time for farmers and local agricultural input suppliers to respond prior to planting. Persisted SSTs are the simplest possible SST forecast system, and are considered a lower limit, and observed SSTs an upper limit, of the best operational predictability from a given GCM-based seasonal forecast system.

Previous diagnostics identified the first principle component $(P C 1)$ of the GCM precipitation spatial field from $6^{\circ} \mathrm{N}$ to $6^{\circ} \mathrm{S}$ latitude and $33^{\circ} \mathrm{E}$ to $43^{\circ} \mathrm{E}$ longitude as an appropriate predictor of both October-December rainfall total and frequency at a station scale in the study region (Hansen and Indeje, 2004). We generated hindcasts of rainfall totals, rainfall frequency and mean intensity in individual months during the growing season (October-February), by leave-one-out cross-validated linear regression as a function PC1. Cross-validation reduces the risk of artificial prediction skill by ensuring that observations from the forecast period do not directly influence past forecasts, while making efficient use of limited data (Efron and Gong, 1983; Michaelsen, 1987).

A stochastic weather model, parameterized from historic daily weather observations at the Katumani and Makindu stations, generated synthetic realizations of daily rainfall that exactly match forecast monthly totals, and daily temperatures and solar irradiance that are conditioned on the occurrence of precipitation. The underlying stochastic weather generator (Hansen and Mavromatis, 2001) models precipitation occurrence by a two-state, hybrid-order Markov chain that simulates precipitation occurrence with a first-order chain if the previous day was wet, or a second-order chain if the previous day was dry. Precipitation amount on a wet day is sampled from a probability mixture of two exponential distributions, also known as a hyperexponential distribution. Daily minimum and maximum temperature, and a transformation of daily solar irradiance (Hansen, 1999), are sampled from a trivariate, first-order Gaussian process conditioned on the occurrence of precipitation, with correlation coefficients that are held constant across location and season (Richardson, 1982). The method for disaggregating monthly rainfall into daily realizations (Hansen and Ines, 2005) maintains consistency between the precipitation occurrence and intensity components of the weather generator by repeatedly generating a month of stochastic rainfall until the total is sufficiently close (i.e., within 5\%) to the monthly rainfall target, then using a multiplicative shift to exactly match the target.

For each year (1968-2002), APSIM was initialized by running the water balance with 2001 observed weather from 1 August to 30 September, then with 10 realizations of synthetic weather conditioned on predicted monthly rainfall totals from the 1 October forecast date through the remainder of the growing season. Holding initial soil conditions constant is consistent with the formulation of value of information (Eq. (1)), and prevents antecedent rainfall observed prior to the forecast from influencing yield predictions and hence potentially inflating the value of forecasts. Predicted yield was the average of yields simulated with the 10 stochastic weather realizations. Yields simulated with observed weather were also initialized using 2001 observed weather up to the forecast date, as evaluating a forecast system requires that the environment, including antecedent weather and its effect on soil water content, observed at the time of the forecast be held constant (Eq. (2)). For each management scenario, mean yields simulated with disaggregated monthly forecasts were calibrated against the time series of yields simulated with observed weather, using cross-validated linear regression. This ensured that the disaggregation method did not introduce any biases in predicted yields, relative to yields simulated with observed weather, which might bias estimates of forecast value.

\section{Results and discussion}

\subsection{Rainfall-management interactions}

APSIM predicted positive response of yields, averaged across years, to initial increments of $\mathrm{N}$ fertilizer, but decreasing marginal response at increasing fertilizer levels (Fig. 1a). At low stand density, yields decreased slightly at the higher fertilizer N levels. Fertilizer and stand density showed an interacting effect on average yields (Fig. 1a). Responsiveness to fertilizer increased with increasing stand density. The highest average yields were associated with the lowest stand density at low ( $\left.\leqslant 20 \mathrm{~kg} \mathrm{~N} \mathrm{ha}^{-1}\right)$ fertilizer rates, while higher stand densities produced the highest average yields as fertilizer rate increased. Results for Makindu (not shown) show a similar pattern to those presented for Katumani (Fig. 1). Although intensification in the form of increasing $\mathrm{N}$ fertilizer and stand density tended to increase average simulated yields, increasing cost with increasing input use leads to optimum levels well below the yield-maximizing levels (Fig. 1b). Maximum average gross margins resulted from intermediate input levels: $50 \mathrm{~kg}$ fertilizer $\mathrm{N} \mathrm{ha}^{-1}$ and 3.5 plants $\mathrm{m}^{-2}$.

Optimal $\mathrm{N}$ fertilizer rate and stand density varied a great deal among years in response to rainfall variability, but showed only modest positive correlation with seasonal rainfall totals (Fig. 2). To illustrate the interactive effect of rainfall and management, Fig. 1 shows simulated yields and gross margins for the wettest and for the driest third (11 out of 34) of years, based on October-December rainfall total. Simulated yield response to $\mathrm{N}$ fertilizer was greater at high stand density, but more constrained by low stand densities, in wet years (Fig. 1c) than when averaged across all years. Gross margins were maximized at a higher fertilizer rate $\left(80 \mathrm{~kg} \mathrm{~N} \mathrm{ha}^{-1}\right)$ and stand density $\left(5.5\right.$ plants $\left.\mathrm{m}^{-2}\right)$ in wet years. In dry years, simulated yields and gross margins decreased with increasing stand density at all fertilizer rates (Fig. 1e, f). Optimum fertilizer rate $\left(20 \mathrm{~kg} \mathrm{~N} \mathrm{ha}^{-1}\right)$ and stand density (2.2 plants $\mathrm{m}^{-2}$ ) were reduced substantially in dry years.

The interactive effects of rainfall, $\mathrm{N}$ fertilizer use and stand density on yield and profit, evident in Fig. 1, are consistent with existing literature. Crops use a given resource most efficiently when all resources are supplied at optimal levels (de Wit, 1992). Several empirical studies have demonstrated that responsiveness of cereal crops to $\mathrm{N}$ fertilizer, and hence optimal application rate, decreases with decreasing supply of water (Whitfield and Smith, 1989; Christianson and Vlek, 1991; Jones and Wahbi, 1992; Pala et al., 1996). As a consequence, the profitability of fertilizer use and optimal application rates for rainfed agriculture vary considerably from year to year as a function of rainfall (Piha, 1993; Thornton and MacRobert, 1994; Jones et al., 2000). Other studies have shown increases in optimal stand density with increasing water supply (Myers and Foale, 1981; Anderson, 1984). From a review of data from across the West African Fertilizer Evaluation Network, Christianson and Vlek (1991) showed that increasing stand density 


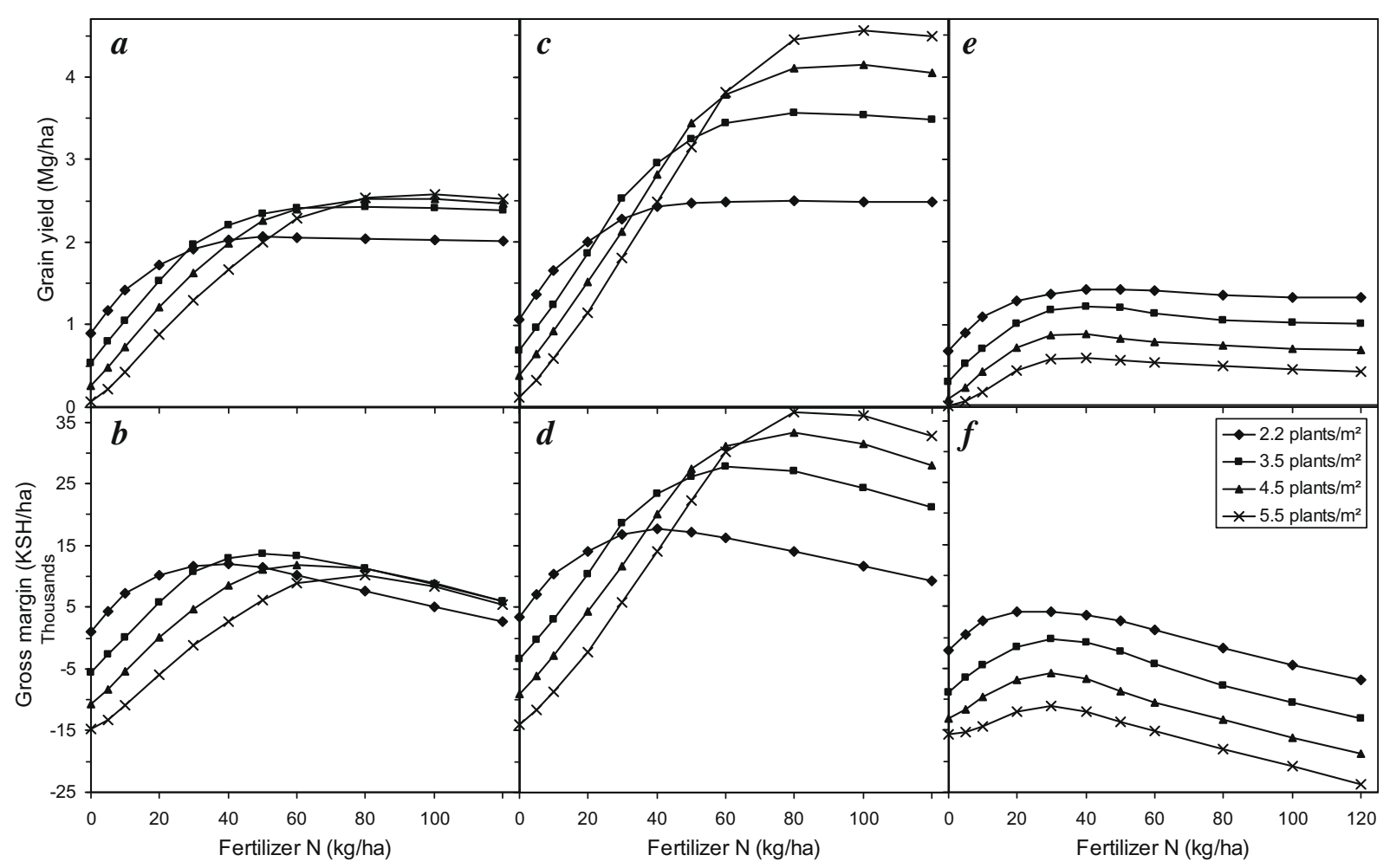

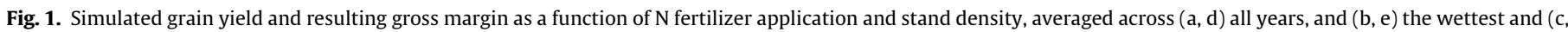
f) the driest third of years, Katumani, 1968-2002.

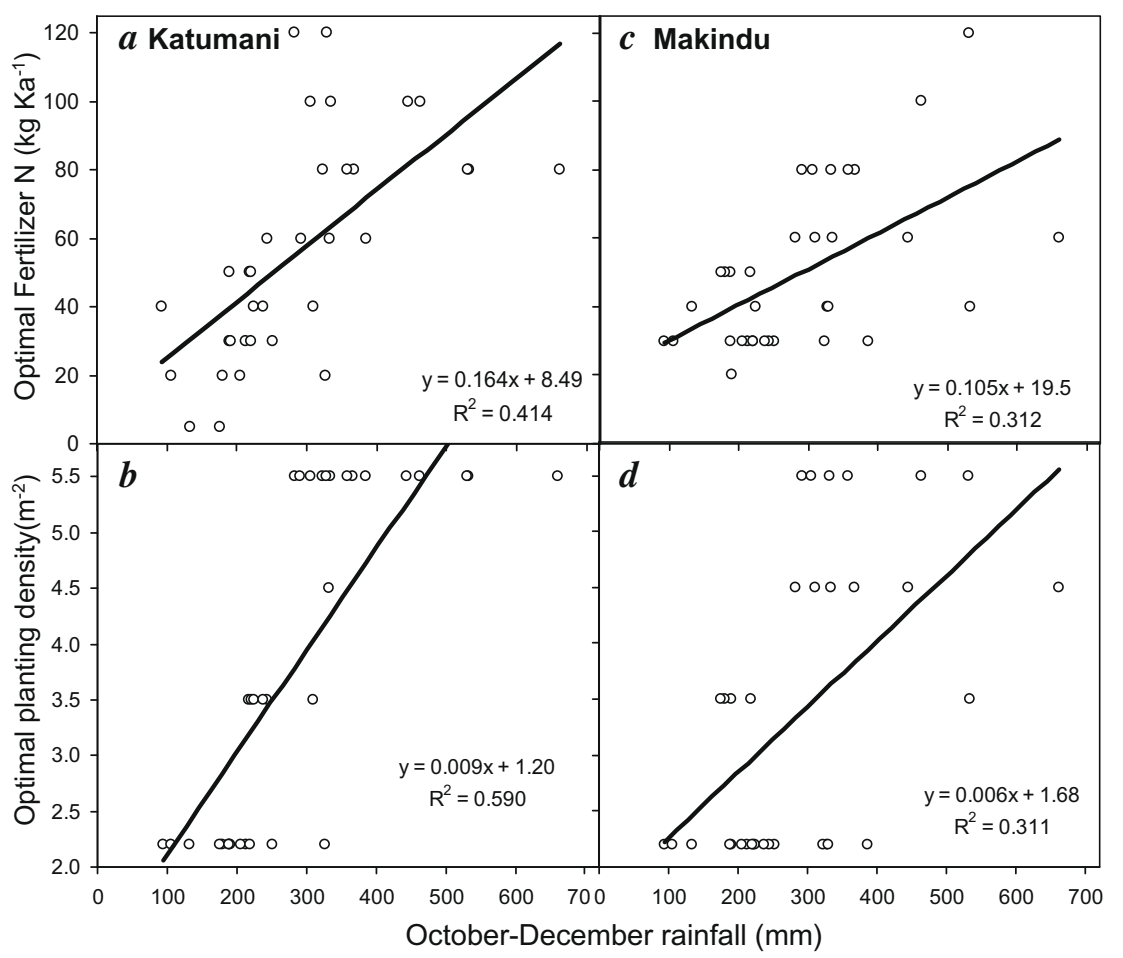

Fig. 2. Yearly profit-maximizing N fertilizer application rates and stand densities vs. October-December rainfall, Katumani and Makindu, $1968-2002$.

increases responsiveness to fertilizer in a wet year but not a dry year. This positive interaction between water supply and optimum input levels suggests that fertilizer and stand density should be adjusted jointly in order to exploit the greatest value from seasonal rainfall forecast information.

\subsection{Rainfall and yield prediction}

GCM forecasts of seasonal or monthly total rainfall based on persisted SSTs did not show significant skill (Table 2). The moderate strength of the relationship between observed rainfall and GCM 
Table 2

Root-mean-squared error (RMSE) of prediction, and correlations of observed precipitation with GCM simulations driven by observed (Obs. SSTs) and persisted SSTs (Pers. SSTs), Katumani and Makindu, 1968-2002.

\begin{tabular}{llllll}
\hline Period & \multicolumn{2}{l}{ RMSE $(\mathrm{mm})$} & & \multicolumn{2}{l}{ Correlation } \\
& Obs. SSTs & Pers. SSTs & & Obs. SSTs & Pers. SSTs \\
\hline Katumani & & & & \\
October-December & 28.2 & 39.5 & & 0.66 & 0.01 \\
October & 37.8 & 42.2 & & 0.43 & 0.10 \\
November & 63.6 & 72.4 & & 0.37 & -0.46 \\
December & 51.6 & 61.8 & & 0.39 & -0.13 \\
Makindu & & & & 0.57 & -0.03 \\
October-December & 45.3 & 57.2 & & 0.30 & 0.01 \\
October & 44.6 & 46.3 & & 0.30 & -0.43 \\
November & 105.3 & 110.3 & & 0.19 & -0.08 \\
December & 57.3 & 77.6 & & 0.61 &
\end{tabular}

simulations driven by observed SSTs is consistent with results reported elsewhere for the Katumani location (Hansen and Indeje, 2004; Ines and Hansen, 2006).

Correlations between yields predicted with GCM rainfall, run with observed SSTs, and simulated with observed weather (Fig. 3) were lower than in previous studies at the Katumani location (Hansen and Indeje, 2004; Hansen and Ines, 2005; Ines and Hansen, 2006). The soil water balance was initialized with observed antecedent weather data from each year of the time series in these studies, whereas the assumptions for estimating forecast value (Eq. (1)) required us to hold initial soil moisture constant (based on August-September 2001 antecedent rainfall). Water stored in the soil profile at the start of a cropping season contributes a degree of predictability to crop yields. Predictability of yields tended to increase with increasing $\mathrm{N}$ fertilizer rates (Fig. 3). We speculate that this was because high $\mathrm{N}$ availability tends to increase the crop's sensitivity to water availability (Fig. 1), allowing it to respond with increased yields in seasons with ample rainfall, but deplete soil moisture early in seasons with inadequate rainfall. As expected, simulated yield showed much lower predictability

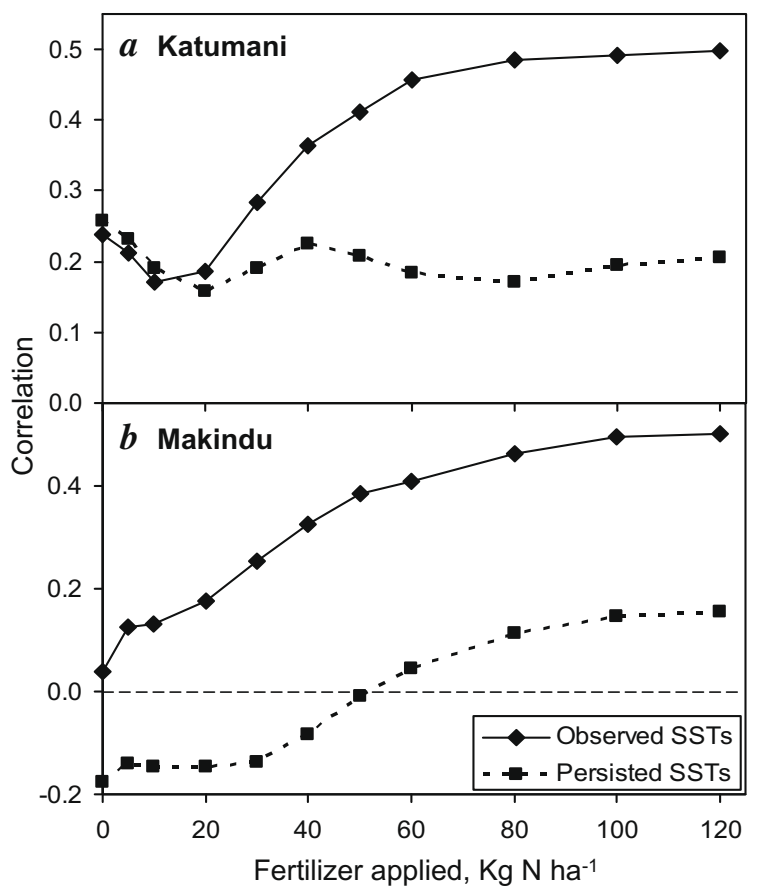

Fig. 3. Correlation of yields simulated with observed weather, and yields simulated using GCM forecasts based on observed and persisted SSTs at (a) Katumani and (b) Makindu, 1968-2002. from GCM hindcasts based on persisted SSTs than from hindcasts based on observed SSTs.

The rainfall simulations driven by observed and persisted SST boundary conditions represent upper and lower bounds, respectively, of the rainfall prediction skill that can currently be achieved operationally from the single GCM (i.e., ECHAM). Although GCM hindcasts run with observed SST are often used to estimate prediction skill, rainfall simulated with SST boundary conditions observed during the forecast season is not a true prediction because it incorporates information that is not available until after the forecast date.

The GCM hindcasts run with persisted SST likely under-represent the skill of available seasonal rainfall forecasts. Eastern Africa (September-November) is one of two regions where Goddard and Mason (2002) noted particular loss of skill from persisted SSTs, relative to a GCM run with observed SSTs. Furthermore, the skill that results from a GCM forced with persisted SSTs drops quickly with lead time. ECHAM skill maps based on gridded rainfall at the coarse scale of the GCM suggest that forecasts based on SSTs persisted from September observations, available in early October well before planting, would likely show significant predictability ( $\mathrm{Li}$ and Goddard, 2005). Rainfall in eastern Africa responds strongly to Indian Ocean SSTs, which show a lagged relationship with ENSO that is generally not apparent in observations until close to the start of the short rains (Goddard and Mason, 2002). Li et al. (2008) showed that running a GCM with SST forecasts derived from a dynamicallycoupled ocean-atmosphere model provides greater precipitation forecast skill, averaged across the global tropical land area, than can be obtained from persisted or other statistical SST forecasts. They also found that averaging results from several SST prediction methods produced forecast skill close to that achieved from observed SSTs particularly for December-February, again averaged across the global tropical landmass. Furthermore, combining multiple GCMs often produces more skillful forecasts than can be obtained from the best individual GCM (Robertson et al., 2004; Hagedorn et al., 2005; Doblas-Reyes et al., 2006). Climate centers such as the International Research Institute for Climate and Society (IRI) routinely integrate multiple GCMs, run with SSTs predicted by several methods, to produce seasonal forecasts. Unfortunately, sufficiently long series of hindcasts that incorporate state-of-the art dynamic SST predictions or multiple-GCM ensemble methods were not available at the time of our analysis.

\subsection{Value of advance climate information under risk neutrality}

Table 3 summarizes the estimated value of three forecast information scenarios: perfect foreknowledge of daily weather, CGM simulations run with observed SSTs, and GCM forecasts run with persisted SSTs. Estimated value of perfect information represents $15-30 \%$ of the average gross value of maize produced, depending on location. At Katumani, optimal response to perfect information increased estimated returns by roughly two-thirds after deducting variable costs of production that include labor. These results suggest that farmers would increase their average income from maize substantially if they could anticipate weather for the upcoming growing season perfectly. The value of perfect information can also be interpreted as the cost of uncertainty due to climate variability.

As expected, the estimated value of seasonal predictions from the CGM simulated with observed SSTs was much lower than the value of perfect information (Table 3). Yet the GCM-based predictions increased average gross margin by $24 \%$ at Katumani. Comparing the value of the GCM-observed SST and the perfect information scenarios suggests that seasonal forecasts that are as skillful as ECHAM simulated with observed SSTs, would allow a farmer to recover about $35 \%$ of the average income lost from climatic uncertainty at Katumani, and about $20 \%$ of the cost of uncertainty 
Table 3

Estimated value of forecast information.

\begin{tabular}{|c|c|c|c|c|c|c|}
\hline \multirow[t]{2}{*}{ Information } & \multicolumn{2}{|c|}{ Value (KSH ha ${ }^{-1} \mathrm{y}^{-1}$ ) } & \multicolumn{2}{|c|}{$\%$ of gross receipts } & \multicolumn{2}{|c|}{$\%$ of gross margin } \\
\hline & Katumani & Makindu & Katumani & Makindu & Katumani & Makindu \\
\hline \multicolumn{7}{|l|}{ Including labor cost } \\
\hline Perfect information & 9333 & 6851 & $23.9 \%$ & $14.7 \%$ & $68.7 \%$ & $43.6 \%$ \\
\hline GCM, observed SSTs & 3277 & 1383 & $8.4 \%$ & $3.0 \%$ & $24.1 \%$ & $8.8 \%$ \\
\hline GCM, persisted SSTs & -794 & -1289 & $-2.0 \%$ & $-2.8 \%$ & $-5.8 \%$ & $-8.2 \%$ \\
\hline \multicolumn{7}{|l|}{ No labor cost } \\
\hline Perfect information & 11,657 & 7268 & $29.9 \%$ & $15.6 \%$ & $44.2 \%$ & $23.6 \%$ \\
\hline GCM, observed SSTs & 4295 & 734 & $11.0 \%$ & $1.6 \%$ & $16.3 \%$ & $2.4 \%$ \\
\hline GCM, persisted SSTs & 31 & -1066 & $0.1 \%$ & $-2.3 \%$ & $0.1 \%$ & $-3.5 \%$ \\
\hline
\end{tabular}

at Makindu. At both sites, omitting labor expenditure from the enterprise budget increased average optimum planting density and $\mathrm{N}$ fertilizer amount in response to forecasts based on observed SSTs. This increased yield enough to compensate for increased cost of seed and $\mathrm{N}$, and therefore increase forecast value on an absolute basis, at Katumani but not at Makindu. Because labor hired from outside the household is a substantial portion of total production cost, omitting hired labor expenditure from the enterprise budget increased average gross margins enough to reduce the value of the information as a fraction of average gross margin at both sites.

Although optimal input levels varied considerably among years, input use averaged among years changed little $(<15 \%)$ in response to the various forecast information scenarios (Table 4). Perfect information increased average yields substantially at both locations. A yield increase without a proportional increase in input use suggests that advance information permitted costly inputs to be used more efficiently. Nitrogen fertilizer use efficiency increased at both locations, but the increase was lower at Katumani where average $\mathrm{N}$ use decreased than at Makindu where average $\mathrm{N}$ use increased. At Katumani, response to GCM forecasts based on persisted SSTs increased average gross margins by increasing average yields and hence gross receipts, regardless of whether estimates accounted for labor cost. However, most of the value of the forecasts based on persisted SSTs at Makindu resulted from reduced expenditure on seed and planting labor associated with reduced average planting density.

Forecasts based on the GCM run with persisted SSTs showed negative or near-zero value largely because they did not show significant positive prediction skill. In principle, forecast value should not be negative, as a rational decision maker would default to management optimized for climatology if the forecast system performs worse than the climatological distribution. However, the cross-validation procedure that we employed to prevent artificial skill can produce "negative skill" (i.e., predictions that are negatively correlated with observations) when predictability is very weak (Barnston and van den Dool, 1993). Unlike the rational farmer, the analytical procedure optimized management for yields simulated with the calibrated, cross-validated hindcasts, even when resulting average gross margins fell below the average for climatology-based management.

Profit-maximizing levels of production inputs were sensitive to prices, particularly the ratio of crop price to input prices. At Katumani, estimated value of forecasts from the GCM run with observed SSTs did not change monotonically with prices of inputs ( $\mathrm{N}$ fertilizer, seed or labor) or with farmgate maize grain price (Fig. 4). Information value was far more sensitive to grain price than to prices of any of the production inputs. Increasing grain price tended to increase forecast value. Value of information showed a weak, generally negative response to the prices of labor and fertilizer, and inconsistent response to variations in seed price.

Estimated value of information did not vary smoothly with changes in prices. The small, abrupt jumps apparent in Fig. 4 are likely an artifact of the optimization procedure, which searched for the maximum gross margins among a limited set ( 11 fertilizer levels $\times$ four planting densities) of discrete management combinations. Differences between the actual optimum (based on crop model response and the resulting enterprise budget) and the selected management strategy likely contributed both to the lack of smoothness in response to changing prices and to some of the negative estimates of forecast information value. The non-smooth response due to the discrete optimization procedure may be compoinded by the tendency of dynamic, highly nonlinear crop

Table 4

Average optimal stand density and $\mathrm{N}$ fertilizer applied as a function of forecast information, and resulting average grain yield and $\mathrm{N}$ use efficiency.

\begin{tabular}{|c|c|c|c|c|c|c|c|c|c|c|c|c|}
\hline \multirow[t]{3}{*}{ Forecast information } & \multirow{2}{*}{\multicolumn{2}{|c|}{$\begin{array}{l}\text { Stand density } \\
\text { (plants } \mathrm{m}^{-2} \text { ) }\end{array}$}} & \multirow{2}{*}{\multicolumn{2}{|c|}{$\begin{array}{l}\mathrm{N} \text { fertilizer } \\
\left(\mathrm{kg} \mathrm{N} \mathrm{ha}^{-1}\right)\end{array}$}} & \multicolumn{4}{|c|}{ Grain yield } & \multicolumn{4}{|c|}{$\mathrm{N}$ use efficiency } \\
\hline & & & & & \multicolumn{2}{|c|}{$\mathrm{Mg} \mathrm{ha}^{-1}$} & \multicolumn{2}{|c|}{$\%$ change $^{c}$} & \multicolumn{2}{|c|}{$\mathrm{kg}$ grain $\mathrm{kg}^{-1} \mathrm{~N}$} & \multicolumn{2}{|c|}{$\%$ change $^{c}$} \\
\hline & $\mathrm{Kat}^{\mathrm{a}}$ & $\mathrm{Mak}^{\mathrm{b}}$ & $\mathrm{Kat}^{\mathrm{a}}$ & $\overline{\text { Mak }^{\mathrm{b}}}$ & $\mathrm{Kat}^{\mathrm{a}}$ & Mak $^{\mathrm{b}}$ & $\mathrm{Kat}^{\mathrm{a}}$ & $\mathrm{Mak}^{\mathrm{b}}$ & $\mathrm{Kat}^{\mathrm{a}}$ & Mak $^{\mathrm{b}}$ & $\mathrm{Kat}^{\mathrm{a}}$ & Mak $^{\mathrm{b}}$ \\
\hline \multicolumn{13}{|l|}{ Including labor cost } \\
\hline Climatology & 3.5 & 5.5 & 50 & 60 & 2.34 & 2.80 & & & 46.8 & 46.6 & & \\
\hline Perfect & 3.9 & 4.4 & 56 & 53 & 3.10 & 3.12 & $32.4 \%$ & $11.7 \%$ & 55.2 & 58.8 & $17.8 \%$ & $26.2 \%$ \\
\hline GCM, OSST ${ }^{\mathrm{d}}$ & 3.4 & 4.8 & 50 & 60 & 2.57 & 2.82 & $9.6 \%$ & $1.0 \%$ & 51.3 & 47.0 & $9.6 \%$ & $1.0 \%$ \\
\hline GCM, PSST & 3.3 & 5.3 & 50 & 66 & 2.27 & 2.73 & $-3.0 \%$ & $-2.5 \%$ & 45.1 & 41.6 & $-3.6 \%$ & $-10.7 \%$ \\
\hline \multicolumn{13}{|l|}{ No labor cost } \\
\hline Climatology & 3.5 & 5.5 & 50 & 60 & 2.34 & 2.80 & & & 46.8 & 46.6 & & \\
\hline Perfect & 3.9 & 4.4 & 57 & 55 & 3.11 & 3.14 & $32.8 \%$ & $12.4 \%$ & 54.5 & 56.7 & $16.4 \%$ & $21.6 \%$ \\
\hline GCM, OSST ${ }^{d}$ & 3.7 & 5.0 & 56 & 63 & 2.65 & 2.83 & $13.3 \%$ & $1.3 \%$ & 47.0 & 45.2 & $0.3 \%$ & $-3.0 \%$ \\
\hline GCM, PSST & 3.7 & 5.4 & 59 & 69 & 2.41 & 2.78 & $2.9 \%$ & $-0.5 \%$ & 41.2 & 40.6 & $-12.1 \%$ & $-12.8 \%$ \\
\hline
\end{tabular}

\footnotetext{
a Katumani.

b Makindu.

c Relative to management optimized for climatology.

d GCM run with observed SSTs.

e GCM run with persisted SSTs.
} 


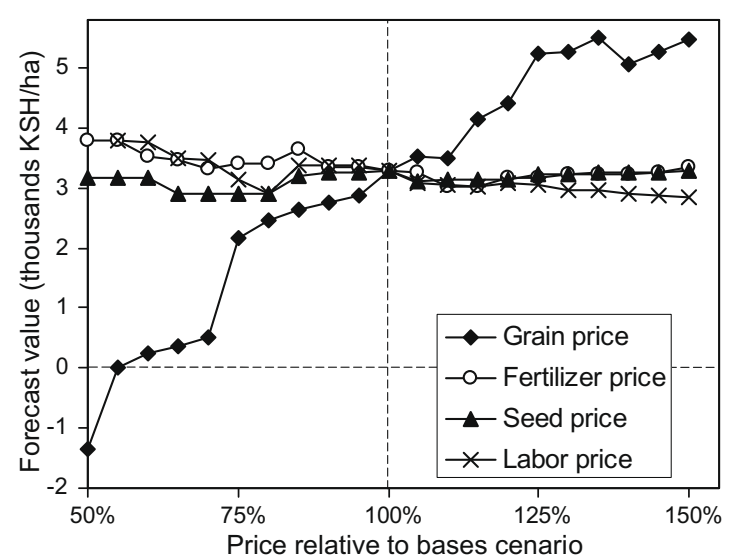

Fig. 4. Sensitivity of forecast value to proportional changes in the prices of maize grain, fertilizer, seed and labor, Katumani, 1968-2002. Forecasts are based on the GCM run with observed SSTs.

simulation models to exhibit complex, irregular response surfaces to management variables (Royce et al., 2001).

\subsection{Risk implications of forecast response}

Forecast value is defined in terms of expected values, and estimated by averaging returns to management, optimized with and without forecast information, across years (Eq. (1)). Yet in particular years, farmers may experience lower returns or greater losses by responding optimally to the forecast than by optimizing management based on climatology. This is the basis for concern that relatively poor, risk-averse farmers would not be able to use seasonal forecast information because they cannot bear the risk of a "wrong forecast" (e.g., Hulme et al., 1992; Blench, 1999, 2003; Broad and Agrawala, 2000; Lemos and Dilling, 2007). While the notion of a "wrong forecast" is inconsistent with the probabilistic nature of seasonal climate prediction, the profit-maximizing farmer who fails to adjust management for risk could reduce income by responding to forecasts in particular years when the climatic outcome is in the tails of the forecast distribution. We therefore examine the risk implications of responding to forecasts in the context of model-based results, using GCM hindcasts simulated with observed SSTs.

In our analyses, returns to management conditioned on forecasts were lower than returns to management conditioned on climatology in $25 \%$ of years at Katumani and $34 \%$ of years at Makindu (Fig. 5), even though average returns were higher. The potential of obtaining lower returns is clearly of greater concern to the poor farmer in a climatically-adverse year when production and income are insufficient to meet household consumption requirements and debt obligations, than in a more favorable year when production and income exceed needs. At both sites, the likelihood of doing worse using forecasts and the magnitude of loss (relative to optimal management conditioned on climatology) were greater in relatively high income years when farmers can better handle the relative loss (Fig. 6). This tendency was due primarily to a greater range of deviations in returns to forecast-based vs. climatologybased management in relatively high-income years.

Stochastic dominance provides a more rigorous basis for assessing the acceptability of the risks associated with optimal use of forecasts for a class of rational decision makers that seek to maximize expected utility and conform to a set of axioms (ordering, transitivity, continuity, independence) (von Neumann and Morgenstern, 1944; Anderson et al., 1977) that define "rational" decision making in the face of risk. Consider a rational decision maker who seeks to maximize the expected value of a utility func-

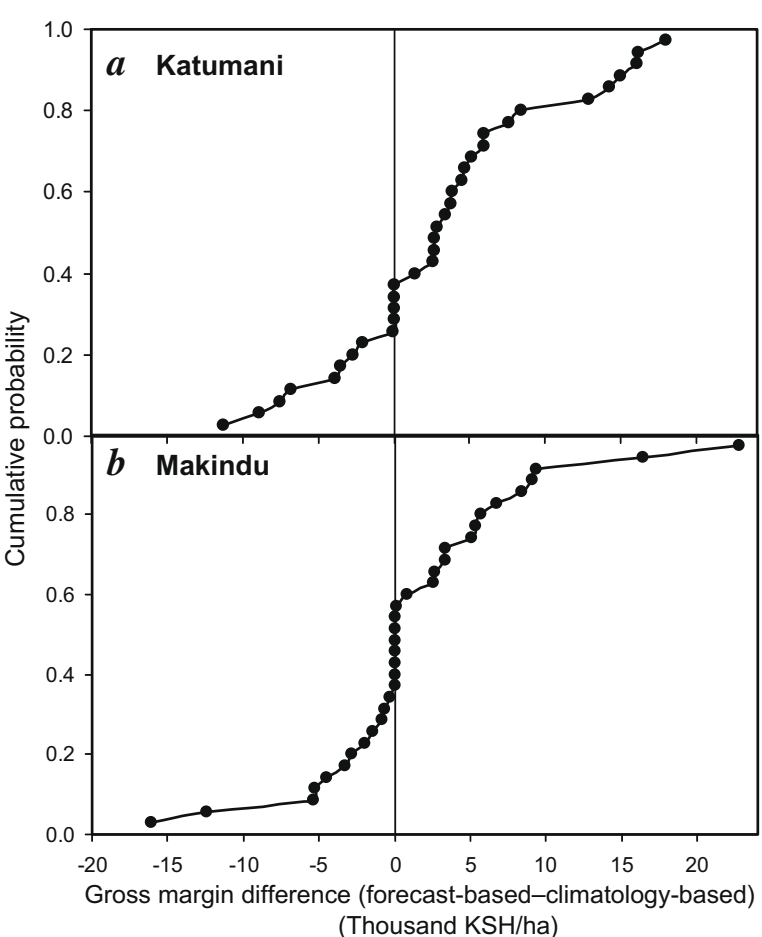

Fig. 5. Cumulative distribution of the benefit from using forecasts, expressed as the difference in gross margin between management optimized to the forecast and management optimized to climatology in a given year at (a) Katumani and (b) Makindu, 1968-2002. Forecasts are based on the GCM run with observed SSTs.

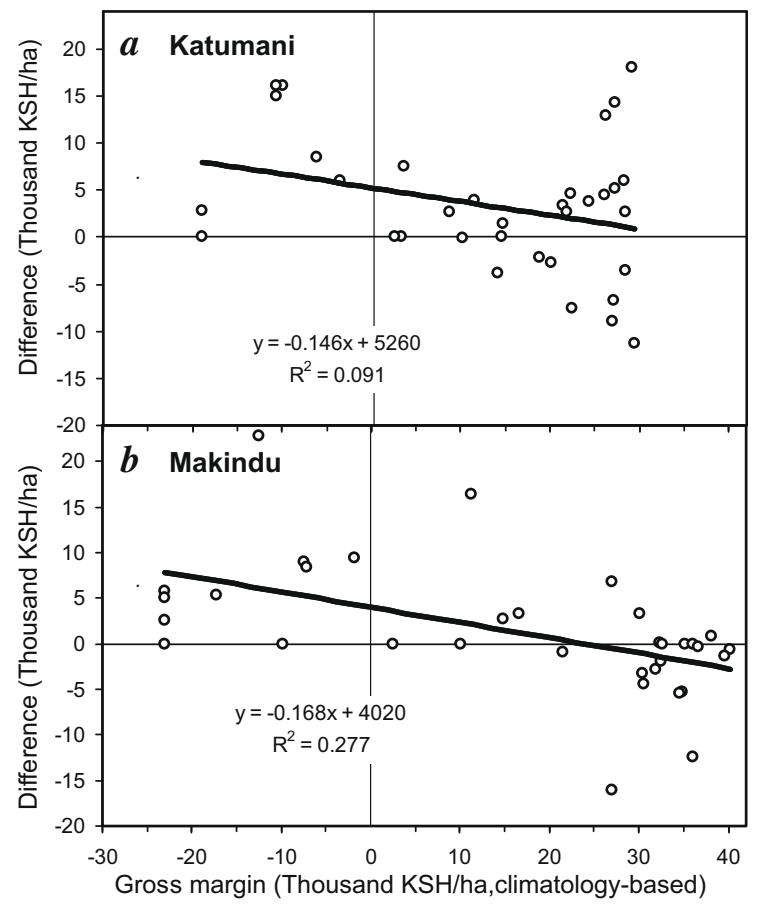

Fig. 6. The benefit from using forecasts, expressed as the difference in gross margin between management optimized to the forecast and management optimized to climatology in a given year, as a function of gross margin from optimal management based on climatology at (a) Katumani and (b) Makindu, 1968-2002. Forecasts are based on the GCM run with observed SSTs.

tion $U(x)$, and who prefers more over less (i.e., $U^{\prime}(x)>0$ ) but who is averse to risk (i.e., $U^{\prime \prime}(x)<0$ ) over the range of variability of stochastic returns $x$. The decision maker is faced with a choice 
between two management strategies $A$ and $B$, with stochastic returns expressed as cumulative distribution functions (CDFs) $F_{A}(x)$ and $F_{B}(x)$. The second-degree stochastic dominance criterion states that such a decision maker would prefer strategy $A$ if the cumulative area under $F_{A}$ is less than or equal to the cumulative area under $F_{B}$ at every point $\xi$ along the distribution, or

$\int_{-\infty}^{\xi} F_{A}(x) d x \leqslant \int_{-\infty}^{\xi} F_{B}(x) d x \quad \forall \xi$

(Hadar and Russell, 1969; Anderson et al., 1977). This holds for any non-negative degree of risk aversion.

We compared distributions of gross margins from the forecastbased (i.e., $\mathbf{x}^{*} \mid F_{i} i=1 . . n$, Eq. (1)) and the climatology-based management strategies $\left(\mathbf{x}^{*} \mid \Theta\right)$ based on the second-order stochastic dominance criterion. We assume that the farmer selects management to maximize expected gross margins for the maize enterprise, just as we did when estimating potential forecast value (Section 3.3). The CDFs of gross margins from the two management scenarios cross, reflecting those weather years when returns to forecastbased management were substantially lower than returns to management optimized for climatology. Yet the cumulative area between the forecast-based and climatology-based gross margin CDFs remains positive at every point (Fig. 7), and the forecastbased management strategy is therefore second-degree stochastic dominant over the climatology-based management strategy at both sites. This implies that the risk-return tradeoff from responding to the forecast is always better than the risk-return tradeoff from ignoring forecasts under the assumptions of our analysis. The substantial probability that responding to the forecast will reduce gross margins in a particular year would neither increase a farmer's risk exposure, nor serve as a disincentive for the rational risk-averse farmer to adopt management conditioned on forecasts regardless of her degree of risk aversion.

An obvious limitation of our analysis is that a risk-averse decision maker would not select maize management strategies that

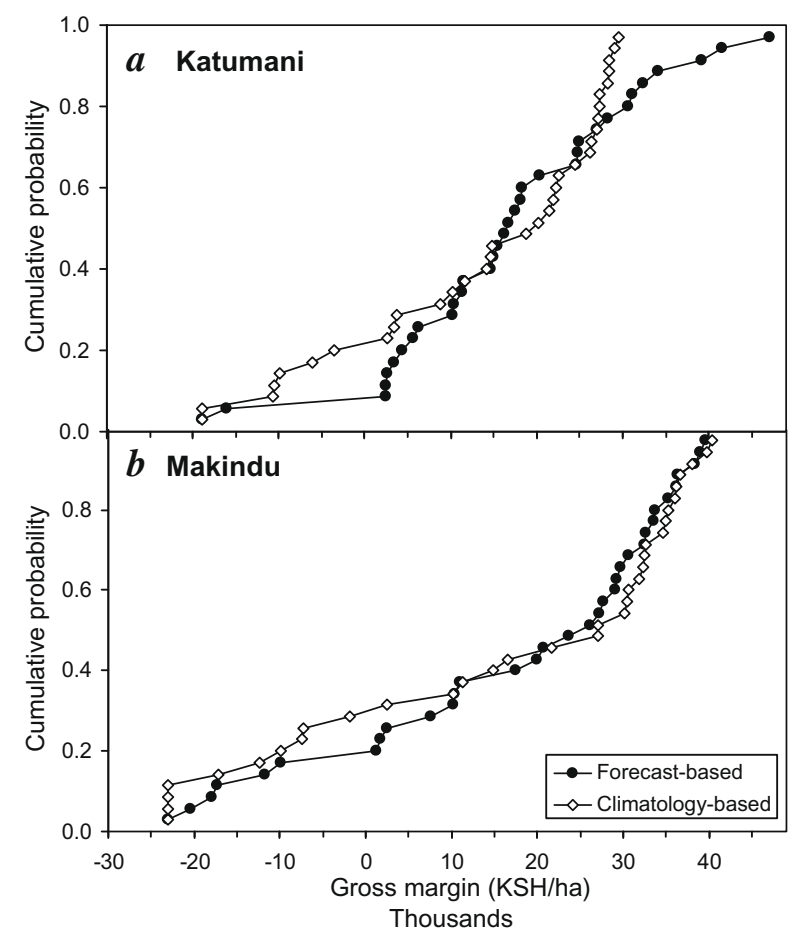

Fig. 7. Cumulative distribution of gross margins from management optimized to forecasts and to climatology at (a) Katumani and (b) Makindu, 1968-2002. Forecasts are based on the GCM run with observed SSTs. maximize expected gross margin. While this simplifying assumption allowed us to estimate the value of advance information for management of a single crop within a diverse farming system, modeling management under risk aversion and assessing impacts on a household's exposure to risk would require more comprehensive analysis at the farm level. This is because imperfect covariance of income from different enterprises results in farm income that is more stable, on average, than the income streams from individual farm enterprises. The assumptions of rationality and accurate understanding of probabilistic forecast and climatological information may be optimistic. Yet given assumptions of rationality and unbiased understanding, the assumption of profit maximization represents a worst-case scenario, as the farmer who is indifferent to risk would not take any precautions to avoid loss of income when outcomes differ greatly from the forecast mean. It is less plausible that the rational farmer might select management that increases risk exposure to an unacceptable level if the analysis considers risk aversion, as the rational risk-averse farmer would never select a management strategy with a risk-return balance that is inferior to the climatology-based strategy. On the other hand, distorted communication or biased perception of either the forecast or climatological probability distribution might lead to decisions that increase risk exposure and hence negate the value of forecast information (Hammer et al., 2001; Hansen and Selvaraju, 2001).

\section{Conclusion}

Soil nutrient depletion is a serious threat to food security and rural livelihoods in sub-Saharan Africa. More efficient management of scarce water and soil nutrients is essential for achieving food security and rural prosperity in the dryland regions of Africa. The APSIM model simulated strong interactions between soil fertility, water availability and planting density that are consistent with published empirical research. Our results illustrate that soil fertility can limit farmers' ability to effectively use available water in seasons with good rainfall, while available soil water in drought years limits returns on investment in fertilizer. The value of advance information about seasonal rainfall resulted from joint management of costly fertilizer, stand density and variable water supply.

To our knowledge, this is the first study to estimate the potential value of seasonal climate forecasts downscaled from a GCM for agricultural management. Results cannot be interpreted as a measure of the potential value of operational forecast for maize management because GCM hindcasts were not available that incorporated dynamic SST forecast or multi-model ensemble methods that represent the state-of-the art of operational seasonal climate prediction. Rather, they indicate the value that could be achieved, under the study's many simplifying assumptions, if forecasts as skillful as the GCM simulations with observed SSTs were available. Yet the prediction skill and hence potential value for maize management that we estimated seem plausible in light of reported improvements in prediction skill that can be achieved from combining SST forecast methods (Li et al., 2008) and combining multiple GCMs - both implemented routinely at the IRI and other climate prediction centers. Determining actual skill from the best operational forecasts at the study locations would require that hindcast runs with multiple SST forecasts, which have recently become available for ECHAM, be replicated for other GCMs used for operational seasonal forecasting; and GCM hindcasts combined and downscaled.

This is, as far as we are aware of, the first quantitative test of the hypothesis that profit-maximizing use of seasonal forecasts can increase the exposure of smallholder farmers to risk. For the context and assumptions of this study, the risk from ignoring forecasts is 
greater than the risk associated with responding to forecasts, and the concern that the risk of a "wrong forecast" is a disincentive to risk-averse farmers is not supported. We argue that, under more realistic assumptions, appropriate use of seasonal climate forecasts would not increase farmers' risk exposure, although communication failures that distort information about forecast uncertainty could. More rigorous evaluation of the risk implications of seasonal climate forecast use by smallholder farmers within our study region would require more comprehensive analysis at the farm level.

Several issues limit the generalizations that can be derived from our results. First, the study locations are not necessarily representative of a larger region. Measures of predictability of rainfall and forecast value were quite different between the two locations. Results were much poorer at Makindu than at Katumani even when using the same soil, cultivar and management options. Based on empirical evidence from Senegal, Moron et al. (2006) suggest that a lack of spatial coherence of rainfall intensities contributes to high sampling error and high spatial variability of estimates of seasonal forecast skill downscaled to individual stations. A robust estimate of downscaled forecast skill and potential forecast value would therefore need to evaluate a much larger set of stations. Second, we expect that spatially-varying soil properties should influence value of forecasts by influencing crop sensitivity to rainfall characteristics and responsiveness to fertilizer applications, although the influence of soil on forecast value has not yet received adequate attention. Finally, the enterprise-level analysis employed in this study ignores many determinants of forecast value that vary among farms. Mjelde et al. (1997) demonstrated that evaluating only a limited subset of potential farm management responses leads to underestimation of seasonal climate forecasts. Farmers who participated in 2-day training workshops at each of the project locations in 2004 collectively identified a rich set of potential management responses related to: timing and method of land preparation, crop and cultivar selection, planting strategy, weeding, soil fertility management, pest management, area cultivated, terrace maintenance, labor procurement and allocation, fencing and cover for livestock, forage management, and grain and fodder storage. However, the available options differ substantially among farms, and particularly between commercial farms, and smallholder farms that tend to be more diversified and much more resource-constrained. A more realistic and robust picture of the potential value of seasonal forecasts to farmers in the study region could be obtained from a farm-level analysis that (a) represents the heterogeneity of farm types, (b) captures farmers' risk attitudes and the multiple sources of risk they face, (c) employs household modeling approaches to account for the multiple objectives and constraints that smallholder farmers face, and (d) is validated by observed farmer decision making over several growing seasons.

As mentioned earlier, evidence indicates that inadequate information content and communication processes constrain smallholder farmers from accessing and benefitting from seasonal forecasts. Overcoming these constraints on a large scale will require substantial investment in the capacity of agricultural extension to integrate climate information into their routine services, in the capacity of meteorological institutions to provide downscaled forecast and historic climate information products tailored to farmer needs, in observing infrastructure and historic data sets, and in evidence of impact needed to mobilize financial resources and institutional support (discussed in Hansen et al., 2007; Brown and Hansen, 2008).

\section{Acknowledgements}

We are grateful for helpful comments from Tony Barnston, and from three anonymous reviewers. This paper was supported in part by a cooperative agreement from the National Oceanic and Atmospheric Administration (NA05OAR4311004); and by a grant from the US Agency for International Development (USAID) - Office of Foreign Disaster Assistance (OFDA) (AID HAD G00-02-00144). The views expressed herein are those of the authors, and do not necessarily reflect the views of NOAA, USAID, or any of their subagencies.

\section{References}

Anderson, W.K., 1984. Plant populations for triticale in a Mediterranean environment. Field Crops Research 8, 281-295.

Anderson, J.R., Dillon, J.L., Hardaker, J.B., 1977. Agricultural Decision Analysis. Iowa State University Press, Ames, Iowa, USA.

Archer, E.R.M., 2003. Identifying underserved end-user groups in the provision of climate information. Bulletin of the American Meteorological Society 84, 15251532 .

Barnston, A.G., van den Dool, H.M., 1993. A degeneracy in cross-validated skill in regression-based forecasts. Journal of Climate 6, 963-977.

Blench, R., 1999. Seasonal climate forecasting: who can use it and how should it be disseminated? Natural Resource Perspectives 47, 1-5.

Blench, R., 2003. Forecasts and farmers: exploring the limitations. In: O’Brien, K. Vogel, C. (Eds.), Coping with Climate Variability: The Use of Seasonal Climate Forecasts in Southern Africa. Ashgate, Hampshire, UK, pp. 59-71.

Broad, K., Agrawala, S., 2000. The Ethiopia food crisis-uses and limits of climate forecasts. Science 289, 1693-1694.

Brown, C., Hansen, J.W., 2008. Agricultural Water Management and Climate Risk. IRI Tech. Rep. No. 08-01. International Research Institute for Climate and Society, Palisades, New York, USA.

Camberlin, P., Philippon, N., 2002. The east African March-May rainy season: associated atmospheric dynamics and predictability over the 1968-97 period. Journal of Climate 15, 1002-1018.

Christianson, C.B., Vlek, P.L.G., 1991. Alleviating soil fertility constraints to food production in West Africa: efficiency of nitrogen fertilizers applied to food crops. Fertilizer Research 29, 21-33.

de Wit, C.T., 1992. Resource use efficiency in agriculture. Agricultural Systems 40, 125-151.

Doblas-Reyes, F.J., Hagedorn, R., Palmer, T.N., 2006. Developments in dynamical seasonal forecasting relevant to agricultural management. Climate Research 33 , 19-26.

Efron, B., Gong, G., 1983. A leisurely look at the bootstrap, the jackknife, and crossvalidation. The American Statistician 37, 36-48.

Friederichs, P., Paeth, H., 2006. Seasonal prediction of African precipitation with ECHAM4-T42 ensemble simulations using a multivariate MOS re-calibration scheme. Climate Dynamics 27, 761-786.

Goddard, L., Graham, N.E., 1999. The importance of the Indian Ocean for simulating precipitation anomalies over eastern and southern Africa. Journal of Geophysical Research 104, 19099-19116.

Goddard, L., Mason, S.J., 2002. Sensitivity of seasonal climate forecasts to persisted SST anomalies. Climate Dynamics 19, 619-632.

Hadar, J., Russell, W.R., 1969. Rules for ordering uncertain prospects. American Economic Review 59, 25-34

Hagedorn, R., Doblas-Reyes, F.J., Palmer, T.N., 2005. The rationale behind the success of multi-model ensembles in seasonal forecasting-I. Basic concept. Tellus Series A. Dynamic Meteorology and Oceanography 57, 219-233.

Hammer, G.L., Hansen, J.W., Phillips, J., Mjelde, J.W., Hill, H.S.J., Love, A., Potgieter, A., 2001. Advances in application of climate prediction in agriculture. Agricultural Systems 70, 515-553.

Hansen, J.W., 1999. Stochastic daily solar irradiance for biological modeling application. Agricultural and Forest Meteorology 94, 53-63.

Hansen, J.W., Indeje, M., 2004. Linking dynamic seasonal climate forecasts with crop simulation for maize yield prediction in semi-arid Kenya. Agricultural and Forest Meteorology 125, 143-157.

Hansen, J.W. Ines, A.M.V., 2005. Stochastic disaggregation of monthly rainfall data for crop simulation studies. Agricultural and Forest Meteorology 131, 233-246.

Hansen, J.W., Mavromatis, T., 2001. Correcting low-frequency variability bias in stochastic weather generators. Agricultural and Forest Meteorology 109, 297310.

Hansen, J.W., Selvaraju, R., 2001. Why do farmers need to understand climate forecast uncertainty? In: Proceedings of the Workshop on Communication of Climate Forecast Information. IRI-CW/01/4. International Research Institute for Climate Prediction, Palisades, New York, USA, pp. 7-9.

Hansen, J.W., Baethgen, W., Osgood, D., Ceccato, P., Ngugi, R.K., 2007. Innovations in climate risk management: protecting and building rural livelihoods in a variable and changing climate. Journal of Semi-Arid Tropical Agricultural Research 4(1). (Published online at <http://www.icrisat.org/Journal/ specialproject.htm>).

Huda, A.K.S., Selvaraju, R., Balasubramanian, T.N., Geethalakshmi, V., George, D.A. Clewett, J.F., 2004. Experiences of using seasonal climate information with farmers in Tamil Nadu, India. In: Huda, A.K.S., Packham, R.G. (Eds.), Using Seasonal Climate Forecasting in Agriculture: A Participatory Decision-making Approach. Australian Centre for International Agricultural Research, Canberra, Australia. 
Hulme, M., Biot, Y., Borton, J., Buchanan-Smith, M., Davies, S., Folland, C., Nichols, N., Seddon, D., Ward, N., 1992. Seasonal rainfall forecasting for Africa part IIapplication and impact assessment. International Journal of Environmental Studies 40, 103-121.

Indeje, M., Semazzi, F.H.M., Ogallo, L.., 2000. ENSO signals in East African rainfall and their prediction potentials. International Journal of Climatology 20, 19-46.

Indeje, M., Ward, M.N., Ogallo, L.J., Davies, G., Dilley, M., Anyamba, A., 2006. Predictability of the normalized difference vegetation index in Kenya and potential applications as an indicator of rift valley fever outbreaks in the Greater Horn of Africa. Journal of Climate 19, 1673-1687.

Ines, A.V.M., Hansen, J.W., 2006. Bias correction of daily GCM rainfall for crop simulation studies. Agricultural and Forest Meteorology 138, 44-53.

Ingram, K.T., Roncoli, M.C., Kirshen, P.H., 2002. Opportunities and constraints for farmers of West Africa to use seasonal precipitation forecasts with Burkina Faso as a case study. Agricultural Systems 74, 331-349.

Jones, M.J., Wahbi, A., 1992. Site-factor influence on barley response to fertilizer in on-farm trials in northern Syria: descriptive and predictive models. Experimental Agriculture 36, 15-26.

Jones, J.W., Hansen, J.W., Royce, F.S., Messina, C.D., 2000. Potential benefits of climate forecasting to agriculture. Agriculture Ecosystems and Environment 82, 169-184.

Keating, B.A., Wafula, B.M., Watiki, J.M., 1992. Exploring strategies for increased productivity. B: the case for maize in semi-arid Eastern Kenya. In: Probert, M.E. (Ed.), A Search for Strategies for Sustainable Dryland Cropping in Semi-arid Eastern Kenya. ACIAR Proceedings No. 41. Australian Centre for International Agricultural Research, Canberra, Australia, pp. 90-101.

Keating, B.A., McCown, R.L., Wafula, B.M., 1993. Adjustment of nitrogen inputs in response to a seasonal forecast in a region of high climatic risk. In: Penning de Vries, F.W.T., Teng, P., Metselaar, K. (Eds.), Systems Approaches for Agricultural Development, vol. 2. Kluwer Academic Publishers, Dordrecht, The Netherlands, pp. 233-252.

Keating, B.A., Carberry, P.S., Hammer, G.L., Probert, M.E., Robertson, M.J., Holzworth, D., Huth, N.I., Hargreaves, J.N.G., Meinke, H., Hochman, Z., McLean, G., Verburg, K., Snow, V., Dimes, J.P., Silburn, M., Wang, E., Brown, S., Bristow, K.L., Asseng, S., Chapman, S., McCown, R.L., Freebairn, D.M., Smith, C.J., 2003. An overview of APSIM, a model designed for farming systems simulation. European Journal of Agronomy 18, 267-288.

Kinyangi, J., Delve, R.J., Probert, M.E., 2004. Testing the APSIM model with data from a phosphorus and nitrogen replenishment experiment on an Oxisol in Western Kenya. In: Delve, R.J., Probert, M.E. (Eds.), Integrated Management in Tropical Cropping: Modelling Nutrient Management in Tropical Cropping Systems. ACIAR Proceedings No.114, ACIAR, Canberra, Australia, pp. 101-109.

Lemos, M.C., Dilling, L., 2007. Equity in forecasting climate: can science save the world's poor? Science and Public Policy 34, 109-116.

Li, S., Goddard, L., 2005. Retrospective forecasts with the ECHAM4.5 AGCM. IRI Tech. Rep. No. 05-2. International Research Institute for Climate and Society, Palisades, New York, USA.

Li, S., Goddard, L., DeWitt, D.G., 2008. Predictive skill of AGCM seasonal climate forecasts subject to different SST prediction methodologies. Journal of Climate 20, 2169-2186.

Meinke, H., Nelson, R., Kokic, P., Stone, R., Selvaraju, R., Baethgen, W., 2006. Actionable climate knowledge: from analysis to synthesis. Climate Research 33, 101-110.

Meza, F.J., Hansen, J.W., Osgood, D., 2008. Economic value of seasonal climate forecasts for agriculture: review of ex ante assessments and recommendations for future research. Journal of Applied Meteorology and Climatology 47, 12691286.

Michaelsen, J., 1987. Cross-validation in statistical climate forecast models. Journal of Applied Meteorology 26, 1589-1600.

Micheni, A.N., Kihanda, F.M., Warren, G.P., Probert, M.E., 2004. Testing the APSIM model with experimental data from the long-term manure experiment at Machang'a (Embu). In: Delve, R.J., Probert, M.E. (Eds.), Integrated Management in Tropical Cropping: Modelling Nutrient Management in Tropical Cropping Systems. ACIAR Proceedings No. 114. ACIAR, Canberra, Australia, pp. 110-117.

Mjelde, J.W., Thomspson, T.N., Nixon, C.J., Lamb, P., 1997. Utilising a farm-level decision model to help prioritise future climate predictions research needs. Meteorological Applications 4, 161-170.

Moron, V., Robertson, A.W., Ward, M.N., 2006. Seasonal predictability and spatial coherence of rainfall characteristics in the tropical setting of Senegal. Monthly Weather Review 134, 3248-3262.

Mutai, C.C., Ward, M.N., 2000. East African rainfall and tropical circulation/ convection on intraseasonal to interannual time-scales. Journal of Climate 8, 1533-1543.

Mutai, C.C., Ward, M.N., Coleman, A.W., 1998. Towards the prediction of the East Africa short rains based on sea surface temperature atmosphere coupling. International Journal of Climatology 18, 975-997.
Myers, R.J.K., Foale, M.A., 1981. Row spacing and population density in grain sorghum-a simple analysis. Field Crops Research 4, 147-154.

Ngugi, R.K., 2002. Climate Forecast Information: The Status, Needs and Expectations among Smallholder Agro-pastoralists in Machakos District, Kenya. IRI Technical Report 02-04. International Research Institute for Climate Prediction, Palisades, New York.

O’Brien, K., Sygna, L., Næss, L.O., Kingamlono, R., Hochobeb, B., 2000. Is Information Enough? User Responses to Seasonal Climate Forecasts in Southern Africa. Center for International Climate and Environmental Research, Oslo.

Ogallo, L.J., Janowiak, J.E., Halpert, M.S., 1988. Teleconnection between seasonal rainfall over East Africa and global sea surface temperature anomalies. Journal of the Meteorological Society of Japan 66, 807-822.

Okwach, G.E., Simiyu, C.S., 1999. Evaluation of long-term effects of management on land productivity in a semi-arid are of Kenya using simulation models. East African Agricultural and Forestry Journal 65, 143-155.

Pala, M., Matar, A., Mazid, A., 1996. Assessment of the effects of environmental factors on the response of wheat to fertilizer in on-farm trials in Northern Syria. Experimental Agriculture 32, 339-349.

Patt, A., Suarez, P., Gwata, C., 2005. Effects of seasonal climate forecasts and participatory workshops among subsistence farmers in Zimbabwe. Proceedings of the National Academy of Sciences 102, 12623-12628.

Phillips, J., 2003. Determinants of forecast use among communal farmers in Zimbabwe. In: O'Brien, K., Vogel, C. (Eds.), Coping with Climate Variability: The Use of Seasonal Climate Forecasts in Southern Africa. Ashgate Publishing, Abingdon, UK, pp. 110-126.

Pickering, N.B., Hansen, J.W., Jones, J.W., Wells, C.M., Chan, V.K., Godwin, D.C., 1994 WeatherMan: a utility for managing and generating daily weather data. Agronomy Journal 86, 332-337.

Piha, M., 1993. Optimising fertiliser use and practical rainfall capture in a semi-arid environment with variable rainfall. Experimental Agriculture 29, 405-415.

Probert, M.E. (Ed.), 1992. A Search for Strategies for Sustainable Dryland Cropping in Semi-arid Eastern Kenya. ACIAR Proceedings No. 41. Australian Centre for International Agricultural Research, Canberra, Australia.

Probert, M.E., Keating, B.A., Larkens, A.G., Siambi, M.N., Undated. Regional assessment of strategies for maize production in semi-arid Eastern Kenya CSIRO Division of Tropical Crops and Pastures Technical Memorandum, Brisbane, Australia.

Rao, M.R., Mathuva, M.N., 2000. Legumes for improving maize yields and income in semi-arid Kenya. Agriculture, Ecosystems and Environment 78, 123-137.

Reynolds, R.W., Smith, T.M., 1994. Improved global sea surface temperature analyses using optimum interpolation. Journal of Climate 7, 929-948.

Richardson, C.W., 1982. Dependence structure of daily temperature and solar radiation. Transactions of the ASAE 25, 735-739.

Robertson, A.W., Lall, U., Zebiak, S.E., Goddard, L., 2004. Improved combination of multiple atmospheric GCM ensembles for seasonal prediction. Monthly Weather Review 132, 2732-2744.

Roeckner, E., Oberhuber, J.M., Bacher, A., Christoph, M., Kirchner, I., 1996. ENSO variability and atmospheric response in a global coupled atmosphere-ocean GCM. Climate Dynamics 12, 737-754

Roncoli, C., Jost, C., Kirshen, P., Sanon, M., Ingram, K.T., Woodin, M., Somé, L. Ouattara, F., Sanfo, B.J., Sia, C., Yaka, P., Hoogenboom, G., 2009. From accessing to assessing forecasts: an end-to-end study of participatory climate forecast dissemination in Burkina Faso (West Africa). Climatic Change 92, 433-460.

Ropelewski, C.F., Halpert, M., 1987. Global and regional scale precipitation patterns associated with the El Niño/Southern Oscillation. Monthly Weather Review 115, 1606-1626.

Royce, F.S., Jones, J.W., Hansen, J.W., 2001. Model-based optimization of crop management for climate forecast applications. Transactions of American Society of Agriculture Engineering 44, 1319-1327.

Shamudzarira, Z., Robertson, M.J., 2002. Simulating response of maize to N fertiliser in semi-arid Zimbabwe. Experimental Agriculture 38, 79-96.

Smith, T.M., Reynolds, R.W., 2003. Extended reconstruction of global sea surface temperatures based on COADS data (1854-1997). Journal of Climate 16, 14951510.

Tarhule, A., Lamb, P.J., 2003. Climate research and seasonal forecasting for West Africans. Bulletin of the American Meteorological Society 84, 1741-1759.

Thornton, P.K., MacRobert, J.F., 1994. The value of information concerning nearoptimal nitrogen fertilizer scheduling. Agricultural Systems 45, 315-330.

von Neumann, J., Morgenstern, O., 1944. Theory of Games and Economic Behavior. Princeton University Press, Princeton, Mass, USA.

Whitfield, D.M., Smith, C.J., 1989. Effects of irrigation and nitrogen growth, light interception and efficiency in light conversion in wheat. Field Crops Research 20, 279-295.

Ziervogel, G., 2004. Targeting seasonal climate forecasts for integration into household level decisions: the case of small farmers in Lesotho. The Geographical Journal 170, 6-21. 